\title{
Dietary Inflammatory Index and its Association with the Risk of Cardiovascular Diseases, Metabolic Syndrome, and Mortality: A Systematic Review and Meta-Analysis
}

Authors

Nazli Namazi', Bagher Larijani², Leila Azadbakht'3, 4, 5

Affiliations

1 Obesity and Eating Habits Research Center, Endocrinology and Metabolism Molecular- Cellular Sciences Institute, Tehran University of Medical Sciences, Tehran, Iran

2 Endocrinology and Metabolism Research Center, Endocrinology and Metabolism Clinical Sciences Institute, Tehran University of Medical Sciences, Tehran, Iran

3 Diabetes Research Center, Endocrinology and Metabolism Clinical Sciences Institute, Tehran University of Medical Sciences, Tehran, Iran

4 Department of Community Nutrition, School of Nutritional Sciences and Dietetics, Tehran University of Medical Sciences, Tehran, Iran

5 Department of Community Nutrition, School of Nutrition and Food Science, Isfahan University of Medical Sciences, Isfahan, Iran

Key words inflammation, cardiovascular disease, metabolic syndrome, death

received $\quad 11.02 .2018$

accepted 13.03.2018

\section{Bibliography}

DOI https://doi.org/10.1055/a-0596-8204

Published online: 3.5.2018

Horm Metab Res 2018; 50: 345-358

(c) Georg Thieme Verlag KG Stuttgart · New York ISSN 0018-5043

\section{Correspondence}

Leila Azadbakht Ph.D.

Department of Community Nutrition

School of Nutritional Sciences and Dietetics

Tehran University of Medical Sciences

P. O. Box: 1416643931

Tehran

Iran

Tel.: + 98/218/895 556, Fax: + 98/218/8984861

azadbakhtleila@gmail.com

\author{
Bagher Larijani M.D. \\ Endocrinology and Metabolism Research Center \\ Endocrinology and Metabolism Clinical Sciences Institute \\ Tehran University of Medical Sciences \\ P. O. Box: 1411413137 \\ Tehran \\ Iran \\ Tel.: + 98/218/822 003, Fax: + 98/218/8220 052 \\ larijanib@tums.ac.ir
}

Supplementary Material for this article is available online at http://www.thieme-connect.de/products.

\section{ABSTRACT}

Findings from previous studies on the association between the Dietary Inflammatory Index (DII) and the risk of chronic diseases and mortality have been inconsistent. We aimed to summarize studies on the association of the DII and the risk for cardiovascular disease (CVD), metabolic syndrome (MetS), and mortality in a systematic review and meta-analysis. We performed a systematic search in PubMed/Medline, Web of Knowledge, and Scopus databases for relevant studies written in English and published until 31 December 2017. Studies that reported the relative risk ( $R R)$, odd ratio $(O R)$ or hazard ratio (HR) for the most pro-inflammatory versus the most anti-inflammatory diets were included. Finally, 17 studies [CVD $(n=6)$, MetS $(n=5)$, mortality $(n=6)]$ were included for systematic review and meta-analysis. Findings indicated a trend toward a positive relationship between the DII and the risk for CVD (pooled RR: 1.35; $95 \%$ Cl: 1.13, 1.60; $\mathrm{I}^{2}: 28.6 \%, \mathrm{p}=0.21$ ), all-cause mortality (pooled HR: 1.21; $95 \% \mathrm{Cl}: 1.09,1.35 ; \mathrm{I}^{2}$ : $72.6 \%, p=0.003$ ), CVD mortality (pooled HR: 1.30, $95 \% \mathrm{Cl}$ : $1.07,1.57 ; I^{2}: 74.0 \%, p=0.009$ ) and cancer mortality (pooled HR: $1.28 ; 95 \% \mathrm{Cl}: 1.07,1.53 ; \mathrm{I}^{2}: 62.5 \%, \mathrm{p}=0.03$ ). However, no significant association was found between the DII and the risk for MetS (pooled RR: 1.01; $95 \% \mathrm{Cl}: 0.82,1.24$; $\mathrm{I}^{2}$ : $32.6 \%$, $\mathrm{p}=0.20$ ). Although in the current meta-analysis the most pro-inflammatory diet versus the most anti-inflammatory diet was not associated with the risk of MetS, we observed a substantial association between the DII and the risk for CVD and all types of mortality. However, further cohort studies in different populations are needed to clarify this association. 


\section{Introduction}

Inflammation is the body's immune response to the presence of inflammatory stimulants or cell damages [1]. However, repeated tissue injuries can cause the release of pro-inflammatory cytokines and trigger chronic systemic inflammation [2]. Chronic systemic inflammation has long been proposed as a main factor in the development and progression of several non-communicable diseases (NCDs), including cardiovascular diseases (CVD), diabetes mellitus, metabolic syndrome (MetS), obesity, and cancer [3]. Individual characteristics, smoking, physical activity, taking some medications as well as diet contribute to chronic inflammation processes [4]. Dietary intake is one of the modifiable factors involved in the development of inflammation and inflammatory-related diseases [5]. Therefore, a substantial amount of attention has been focused on the pro- and anti-inflammatory properties of nutrients and foods.

Recent studies have found that overall dietary composition is more important for predicting the risk of chronic diseases and mortality than specific nutrients [5]. Interactions among nutrients can modify the final effect of a certain dietary component on both inflammatory responses and health outcome [1]. Based on accumulation evidence, the pro- and anti-inflammatory status of many specific foods and nutrients have been determined and presented as the Dietary inflammatory index (DII) [6].

The DII is a valid tool for predicting the levels of inflammatory cytokines like interleukin-6 (IL-6) and C-reactive protein (CRP) as well as related health outcomes based on the inflammatory scores of a diet [7]. The DII has been grounded in accordance with accumulating literature and standardized in regard to the dietary intake of different populations worldwide [8]. It can provide a useful way to estimate the inflammatory nature of an individual's diet based on the pro- and anti-inflammatory of the overall dietary composition, including macronutrients, vitamins and minerals, alcohol intake, and flavonoids [9]. Several studies have reported an association between an increasing DII score and biochemical inflammatory parameters $[6,10]$ leading to the hypothesis that a diet with high levels of pro-inflammatory components might be related to an increased risk for some NCDs and mortality $[11,12]$. Some studies have suggested an association between the DII and CVD $[1,5,13]$, the components of metabolic syndrome [9] and even all-cause mortality $[14,15]$. However, some prior studies did not report any associations [9, 16-18].

To the best of our knowledge, only one narrative review has evaluated the association of the DII with CVD, MetS, and mortality [4], and there is no meta-analysis on this topic. A narrative review by Ruiz-Canela et al., concluded that the DII score can be a suitable tool for estimating the inflammatory status of diet and that helps to determine the association between diet, inflammation and chronic diseases [4]. However, they did not determine the event rate. In light of contradictory findings about the association between diet-related inflammation and the risk of chronic diseases, as well as an increasing interest in revealing the role of a diet with a high DIl score in increasing NCDs, we aim to summarize the association of the DII with CVD, MetS, and mortality for the first time in adult populations.

\section{Materials and Methods}

The present systematic review and meta-analysis follows the principals of the PRISMA (Preferred Reporting Items for Systematic Reviews and Meta-Analyses) statement [19].

\section{Search strategy}

A systematic literature search was performed in four databases PubMed/Medline, Scopus, and Web of Science through 31 December 2017 to identify relevant publications. In the current systematic review, papers which examined the relationship of DII either with CVD, metabolic syndrome or mortality were collected by searching the following MeSH (Medical Subject Headings) and free terms in titles and abstracts: "Dietary inflammatory index" OR "dietary inflammatory score" OR "diet-related inflammation" in combination with "cardiovascular" OR "heart" OR "stroke" OR "coronary" OR “myocardial infarction" OR "metabolic syndrome” OR “mortality” OR "death". The literature search was limited to English language papers.

Additionally, all references of the eligible papers were checked manually to find any relevant studies. The titles and abstracts of papers were examined to screen any potential relevant studies. Then, the full texts of relevant articles were read to identify whether they reported all information that we needed. All aforementioned processes were conducted independently by two reviewers (N.N, L.A). Any disagreement was resolved by consensus.

\section{Inclusion and exclusion criteria}

Only publications that met the following criteria were considered for the meta-analysis: (i) publication with either a cross-sectional or cohort designs, (ii) studies with adult subjects (older than 18 years), (iii) studies which reported risk ratios (RRs), odd ratio (OR) or hazard ratios (HRs) with $95 \%$ Confidence Interval (Cl) for the highest to the lowest DII, and (iv) reported at least one of our interest outcomes (CVD, metabolic syndrome or mortality). They were excluded if they were (i) case-control studies, (ii) grey literature (dissertation, book chapters, abstracts in conferences and interviews), (iii) review papers, and (iv) studies on children or adolescents.

\section{Data extraction}

The following information were extracted by two reviewers (N.N, L.A) separately: (i) publication data (first author's name, year of publication and country), (ii) study design, (iii) participants' age range, (iv) sample size, (v) number of cases, (vi) dietary assessment tool, (vii) method used to diagnosis the presence or absence of each outcome, (viii) risk estimates with their Cls, and (ix) adjusted covariates ( $\triangleright$ Table $\mathbf{1}$ ). If there was a clinical trial, only HRs or RRs for placebo group were reported. Moreover, in studies that the HRs/RRs were reported for a combination of outcomes, they were not included in the meta-analysis. Additionally, if the effect sizes were reported for both healthy and unhealthy subjects at the baseline, only RRs for healthy subjects were considered for quantitative synthesis.

\section{Methodological quality assessment}

We assessed the quality of studies using the Newcastle-Ottawa scale [20]. This checklist has three main sections about (i) selec- 


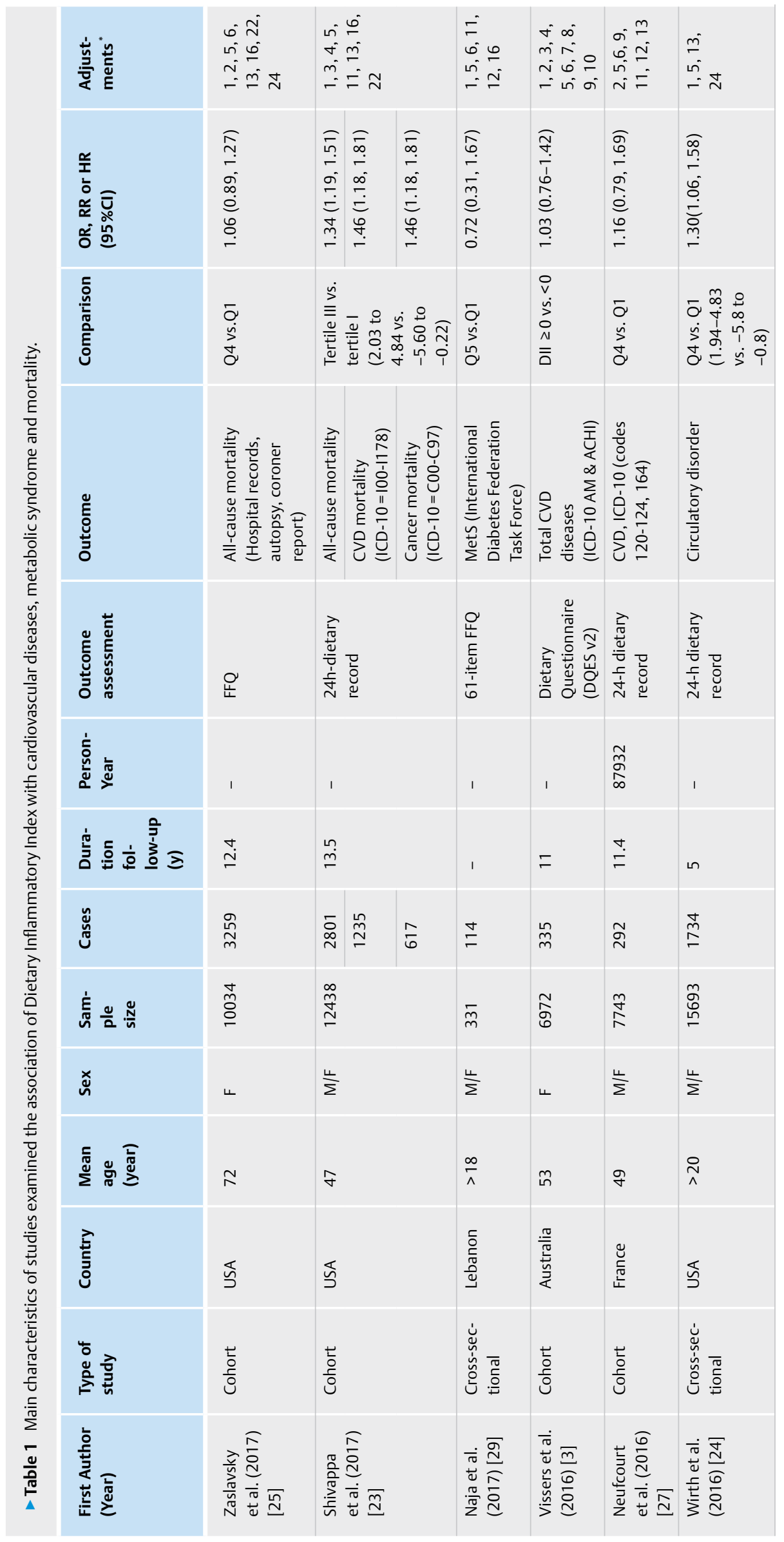




\begin{tabular}{|c|c|c|c|c|c|c|c|c|}
\hline 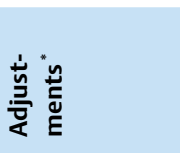 & \multicolumn{3}{|l|}{$\begin{array}{l}\text { in } \\
\dot{+} \\
\stackrel{m}{i} \\
\stackrel{0}{-}\end{array}$} & $\begin{array}{l}0 \\
\text { in } \\
i= \\
i=0 \\
i=\end{array}$ & $\begin{aligned} & 0 \\
= & 0 \\
= & 0 \\
= & \dot{n}\end{aligned}$ & 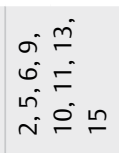 & \multirow{2}{*}{ 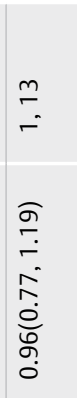 } & \multirow{2}{*}{ 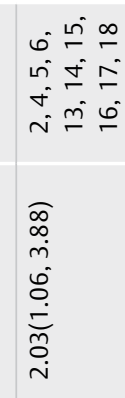 } \\
\hline 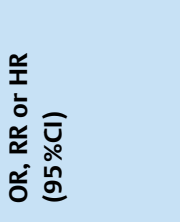 & 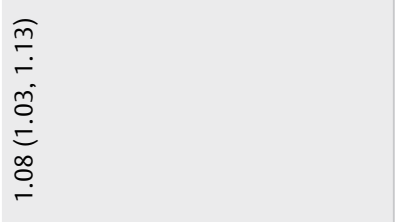 & 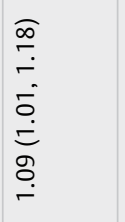 & 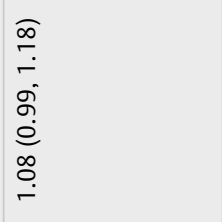 & 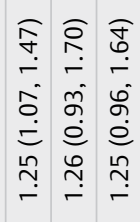 & 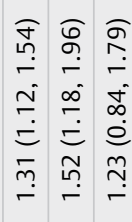 & 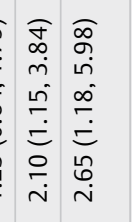 & & \\
\hline 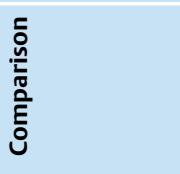 & \multicolumn{3}{|l|}{ 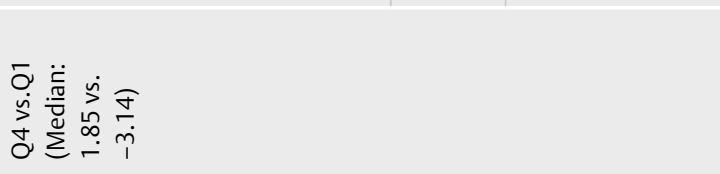 } & $\begin{array}{l}\overline{0} \\
\dot{1} \\
\stackrel{2}{0}\end{array}$ & 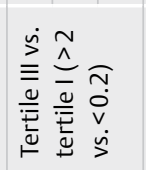 & 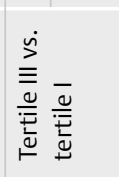 & \multirow{2}{*}{ 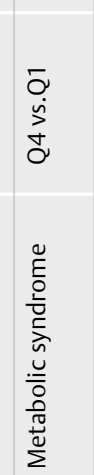 } & $\begin{array}{l}\bar{D} \\
\dot{\Delta} \\
\dot{\Delta}\end{array}$ \\
\hline 气ัّ & 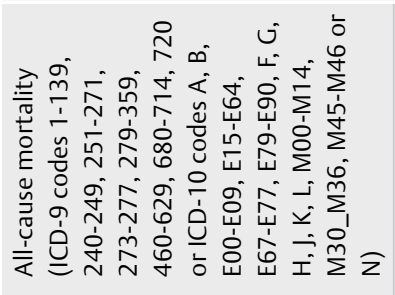 & 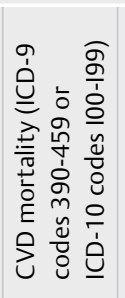 & 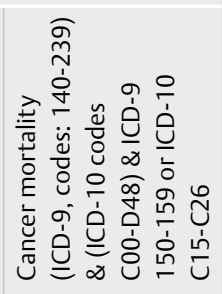 & 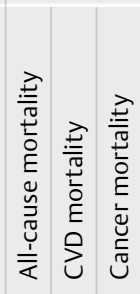 & 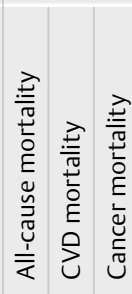 & 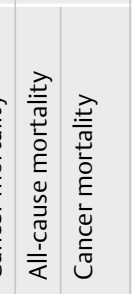 & & 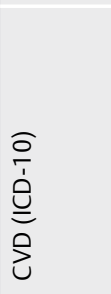 \\
\hline 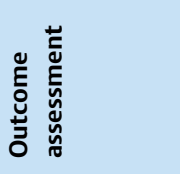 & 안 & & & 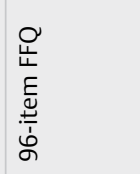 & 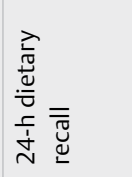 & 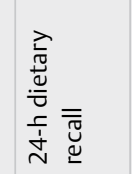 & 안 & 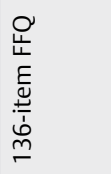 \\
\hline 嵩 & 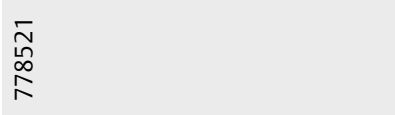 & & & 1 & 1 & & $\Sigma$ & $\begin{array}{l}\stackrel{0}{\circ} \\
\stackrel{\infty}{\circ} \\
\stackrel{-}{0}\end{array}$ \\
\hline 空 & $\hat{\grave{\nu}}$ & & & $\stackrel{\llcorner}{\llcorner}$ & $r$ & 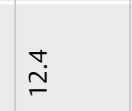 & $\Sigma$ & $\stackrel{\sigma}{\infty}$ \\
\hline $\begin{array}{l}\text { yे } \\
\text { ज̃ } \\
\text { J }\end{array}$ & $\stackrel{m}{\stackrel{m}{\Sigma}}$ & ஸ్రి & 芦 & 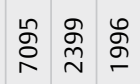 & 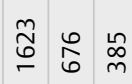 & 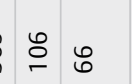 & 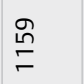 & 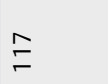 \\
\hline 宗 $\frac{N}{n} \frac{N}{n}$ & 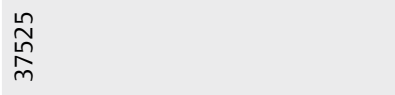 & & & $\underset{\substack{f \\
m}}{\stackrel{m}{m}}$ & $\overline{\tilde{Q}}$ & $\bar{m} \bar{m} \bar{m}$ & 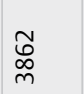 & \begin{tabular}{l}
\multicolumn{5}{c}{} \\
$\substack{\infty \\
\infty}$
\end{tabular} \\
\hline ๑ & 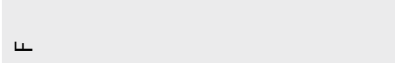 & & & 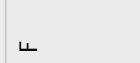 & $\frac{u}{\Sigma}$ & $\frac{u}{\Sigma}$ & $\frac{u}{\Sigma}$ & $\frac{\omega}{\Sigma}$ \\
\hline 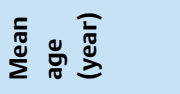 & $\overline{6}$ & & & $\bar{\sigma}$ & $\dddot{q}$ & g & 占 & $\stackrel{\infty}{m}$ \\
\hline 站 & 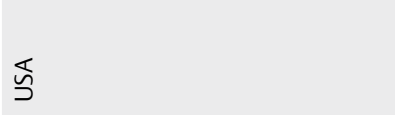 & & & 焉 & 气 & 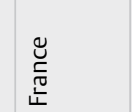 & 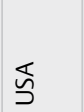 & $\begin{array}{l}\text { 离 } \\
\text { ñ }\end{array}$ \\
\hline 衣 & $\begin{array}{l}\frac{5}{5} \\
\frac{0}{0} \\
\end{array}$ & & & $\begin{array}{l}\text { tั } \\
\text { 응 }\end{array}$ & 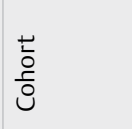 & $\begin{array}{l}\text { tั } \\
\text { 产 } \\
0\end{array}$ & 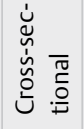 & $\begin{array}{l}\text { to } \\
\text { 홍 }\end{array}$ \\
\hline 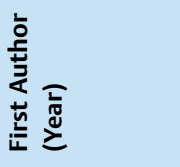 & 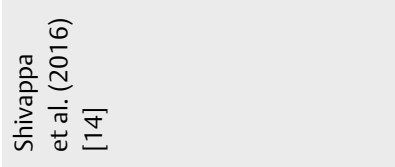 & & & 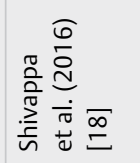 & 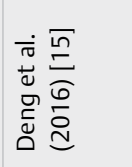 & 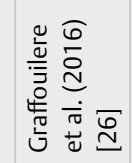 & 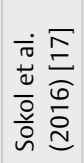 & 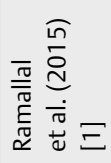 \\
\hline
\end{tabular}




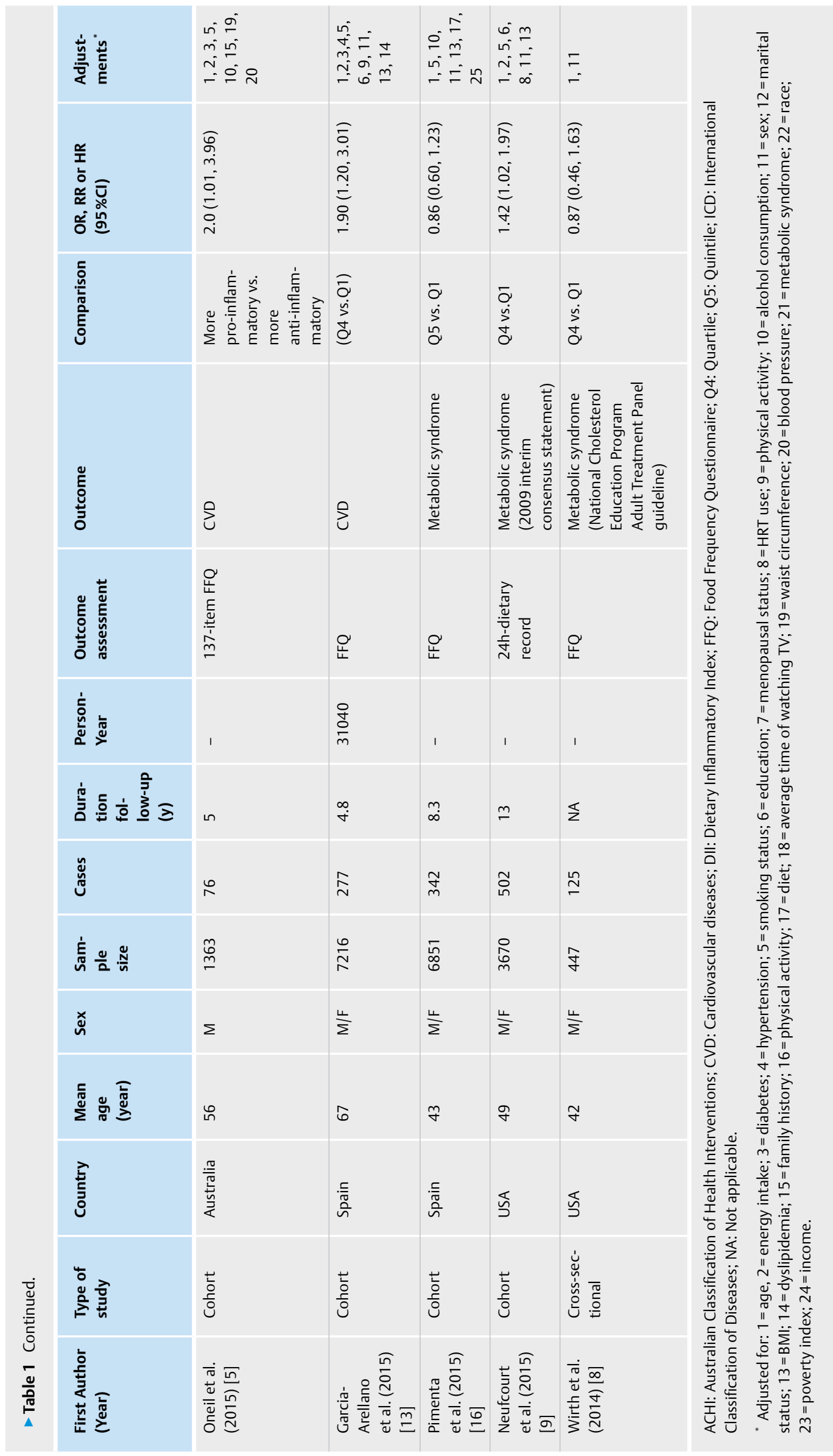


- Table 2 The score for the methodological quality assessment in included papers.

\begin{tabular}{|c|c|c|c|c|}
\hline Author name & $\begin{array}{l}\text { Selec- } \\
\text { tion }\end{array}$ & $\begin{array}{l}\text { Compa- } \\
\text { rability }\end{array}$ & Outcome & $\begin{array}{l}\text { Total } \\
\text { score }\end{array}$ \\
\hline $\begin{array}{l}\text { Zaslavsky et al. } \\
\text { (2017) [25] }\end{array}$ & 3 & 2 & 2 & 7 \\
\hline $\begin{array}{l}\text { Shivappa et al. } \\
\text { (2015) [23] }\end{array}$ & 3 & 2 & 2 & 7 \\
\hline $\begin{array}{l}\text { Naja et al. (2017) } \\
\text { [29] }\end{array}$ & 3 & 2 & 2 & 7 \\
\hline $\begin{array}{l}\text { Vissers et al. } \\
\text { (2016) [3] }\end{array}$ & 3 & 2 & 3 & 8 \\
\hline $\begin{array}{l}\text { Neufcourt et al. } \\
\text { (2016) [27] }\end{array}$ & 2 & 2 & 3 & 7 \\
\hline $\begin{array}{l}\text { Wirth et al. } \\
\text { (2016) [24] }\end{array}$ & 3 & 2 & 1 & 5 \\
\hline $\begin{array}{l}\text { Shivappa et al. } \\
\text { (USA) (2016) [14] }\end{array}$ & 3 & 2 & 3 & 8 \\
\hline $\begin{array}{l}\text { Shivappa et al. } \\
\text { (Sweden) (2016) } \\
{[18]}\end{array}$ & 4 & 2 & 2 & 8 \\
\hline $\begin{array}{l}\text { Deng et al. } \\
\text { (2016) [15] }\end{array}$ & 4 & 2 & 3 & 9 \\
\hline $\begin{array}{l}\text { Graffouilere et al. } \\
\text { (2016) [26] }\end{array}$ & 3 & 2 & 2 & 7 \\
\hline $\begin{array}{l}\text { Sokol et al. } \\
\text { (2016) [17] }\end{array}$ & 3 & 1 & 2 & 7 \\
\hline $\begin{array}{l}\text { Ramallel et al. } \\
\text { (2015) [1] }\end{array}$ & 2 & 2 & 3 & 7 \\
\hline $\begin{array}{l}\text { Oneil et al. } \\
\text { (2015) [5] }\end{array}$ & 2 & 2 & 2 & 6 \\
\hline $\begin{array}{l}\text { Garcia et al. } \\
\text { (2015) [13] }\end{array}$ & 3 & 2 & 2 & 7 \\
\hline $\begin{array}{l}\text { Pimenta et al. } \\
\text { (2015) [16] }\end{array}$ & 2 & 2 & 2 & 6 \\
\hline $\begin{array}{l}\text { Neufcaurt et al. } \\
\text { (2015) [9] }\end{array}$ & 2 & 2 & 3 & 7 \\
\hline $\begin{array}{l}\text { Wirth et al. } \\
(2014)[8]\end{array}$ & 2 & 1 & 1 & 4 \\
\hline
\end{tabular}

tion, (ii) comparability and (iii) outcome. A total score of 9 represents the highest quality. In the present meta-analysis, when a paper obtained more than median score ( $\geq 5)$, it was considered as study with relatively high quality. Similar to the previous processes, this step was performed with two independent investigators (N.N, L.A) and any discrepancies were resolved by the principal investigator (B.L). Scores of the methodological quality for each paper is presented in $>$ Table 2.

\section{Data synthesis and statistical analysis}

RRs or HRs (with $95 \% \mathrm{Cls}$ ) were extracted from each eligible paper to compare the most pro-inflammatory versus the most anti-inflammatory diet. They were converted to logarithmic forms, and standard errors for each study were calculated based on the formula [21]. RRs or HRs for each outcome were pooled with random-ef- fect models using DerSimonian and Laird. Heterogeneity was examined using the I-square $\left(I^{2}\right)$ index. $I^{2}$ values of more than $50 \%$ were considered high heterogeneity [22]. To determine $\mathrm{I}^{2}$ as a heterogeneity index, a random-effect model was used. Moreover, between-study heterogeneity was examined using a fixed-effect model.

In the case of severe heterogeneity, subgroup analysis was used to identify the main possible source of heterogeneity. Whenever possible (at least two effect sizes in each subgroup), the potential sources of heterogeneity for each outcome (CVD, MetS, mortality) were examined based on the following categories: gender (men, women), age (less or more than 49 years old), duration of follow-up (less or $\geq 12.5$ years), dietary assessment tool (FFQ, 24-h dietary record or other assessment), study quality ( $\leq$ or more of 5), country (US, Non-US) and energy adjustment (adjusted, non-adjusted). Moreover, mortality outcome was sub-grouped based on the causes of mortality (all-cause, CVD and cancer).

We examined the robustness of our findings using sensitivity analysis. The analysis was conducted after eliminating one study at a time to identify how much each study impacted the overall effect size. To examine the publication bias for each outcome, the Egger's regression test was used. If publication bias existed, trim and fill was used to correct the results. $p$-Value $<0.05$ was considered statistically significant. All data analyses were conducted using Stata 12.0 software (Stata Corp LP, College Station, TX, USA).

\section{Results}

\section{Literature search}

We identified a total of 153 papers (containing 57 duplications) through electronic databases, as well as two eligible papers from the reference lists of papers. In the stage of screening based on titles and abstracts of 96 included papers, 64 papers did not meet the inclusion criteria. Sixty-two irrelevant studies and two review paper were excluded from additional examinations. Through fulltext assessment of potential eligible studies, we excluded 15 more publications due to the following reasons: Irrelevant $(n=11)$, dietary patterns (DASH, Healthy eating index, etc.) $(n=3)$, case-control design $(n=1)$. Finally, 17 papers were chosen for inclusion in both qualitative and quantitative syntheses ( $>$ Fig. 1). They were examined the association between the most pro-inflammatory versus the most anti-inflammatory diets on the risk of CVD, MetS and mortality.

\section{Study characteristics}

The main characteristics of the 17 cohort studies included in the meta-analysis are indicated in $>$ Table 1. As DIl was introduced for the first time in 2009 [7], all included studies were related to the recent years, 2014 to 2017 . In various populations including the USA $(n=8)[8,9,14,15,17,23-25]$, Australia $(n=2)[3,5]$, France $(n=2)[26,27]$, Spain $(n=3)[1,13,16]$, Sweden $(n=1)[28]$, and Lebanon $(n=1)$ [29], the association between DII and CVD $(n=6)$ $[1,3,5,13,24,27]$, MetS $(n=5)[8,9,16,17,29]$ or mortality $(n=6)$ $[14,15,23,25,26,28]$ was examined. Of the included papers, four studies had cross-sectional design $[8,17,24,29]$ and for the remaining papers $(n=13)$ prospective cohort design was used. The 
number of participants varied between 331 and 37525 participants with average age 38 to 72 years. In most studies $(n=12)[1,8$, $9,13,15-17,23,24,26,27,29]$, the effect size for both genders in combination was reported. However, some studies were conducted on either women $(n=4)[3,14,25,28]$ or men $(n=1)[5]$. Overall, 37750 cases among 180248 participants throughout 4.8 and 20.7 years follow-up duration were reported. Person-year was only reported in four cohort studies $[1,13,14,27]$ which ranged between 31040 to 778 521. For calculating DII, all studies used either food frequency questionnaire (FFQ) $(n=10)[1,5,8,13,14$, $16,17,25,28,29]$ or 24 -h dietary records $(n=7)[9,15,23,24$, $26,27]$. Various cut off points were considered for both the most proand the most anti-inflammatory diets as presented in $>$ Table $\mathbf{1}$.

According to the Newcastle-Ottawa checklist, the methodological quality in all included studies except one [8] was high (score $\geq 5$ ). The scores for quality in 13 studies were equal or more than 7 ( $\triangleright$ Table 2). In all studies, adjusted RRs/ORs/HRs was reported. However, the effect sizes were controlled for different number and type of potential confounding factors. They had adjusted mostly for smoking status $(n=15)[1,3,5,8,9,13-16,23,25-30]$, age $(n=14)[3,8,9,14-17,23,25,26,28-30]$, BMI $(n=12)[1,9,13-$ $17,23-28]$, energy intake $(n=10)[1,3,5,9,13,14,23,25-28]$, sex $(n=9)[8,9,13,15,16,23,26,27,29]$, and physical activity $(n=8)$ $[1,3,13,15,23,26-28]$.

\section{Findings of systematic review}

All the studies except two $[3,27]$ that reported ORs or RRs for CVD, found an association between the consumption of the most pro-inflammatory diet versus the most anti-inflammatory diet and the risk of CVD events. Based on the study by Vissers et al, no statistically significant association was observed between DII and the risk of total CVD, stroke, ischemic heart disease or cerebrovascular disease in Australian women [3]. Neufcourt et al., also reported that there was no association between the DII and total CVD events. However, when they considered the subclasses of CVD, a significant association between DII and the risk of myocardial infarction was observed [27].

Among five studies $[8,9,16,17,29]$ in which the relationship between the DII and the risk of MetS were examined; only Neufcaurt et al., found a significant association [9]. The study concluded that the most inflammatory diet considerably increased the risk of MetS in American population in a 13 year follow- up. Moreover, there were rather similar findings on the association between the DII and CVD or all-cause mortality. Three $[14,15,23]$ of four prospective cohort studies on CVD mortality and all five studies except one [25] on all-cause mortality $[14,15,23,26,28]$ reached significant associations. However, the findings on mortality from cancer were contradictory. Three $[14,15,28]$ of five prospective studies failed to show an association between the DII and the risk of cancer mortality. Graffouillere et al. examined the association of the DIl with mortality from CVD or cancer (in combination) but did not find a significant association [26].

\section{Findings from meta-analysis on DII and the risk of CVD}

Based on the meta-analysis of six effect sizes with a total number of 2,831 cases among 57781 people, we found a significant asso- ciation between DIl and the risk of CVD (pooled RR: 1.35; $95 \% \mathrm{Cl}$ : $1.13,1.60)$ with no significant between-study heterogeneity $\left(I^{2}=28.6 \%, p=0.21\right)$ ( $>$ Fig. 2 ).

Although the heterogeneity was less than $50 \%$, we conducted further analysis to examine the effects of parameter on the overall effect size. Stratification by dietary assessment tool $(p=0.53)$ and energy adjustment $(p=0.40)$ showed no significant differences between two sub-groups ( $\triangleright$ Table 3 ). Furthermore, the methodological quality in all included studies was high (score $\geq 5$ ). Therefore, stratification by quality was not possible.

\section{Findings from meta-analysis on DII and the risk of MetS}

Overall, pooling four effect sizes indicated that the consumption of the most pro-inflammatory vs. the most anti-inflammatory diet was not significantly associated with the risk of MetS (pooled

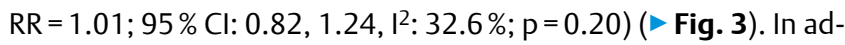
dition, due to limited studies for MetS, only stratification by the type of study was possible. In neither cohort (pooled RR=1.11; $95 \%$ $\left.\mathrm{Cl}: 0.68,1.82, \mathrm{I}^{2}: 75.5 \% ; \mathrm{p}=0.04\right)$ nor cross-sectional studies (pooled RR = 0.94; $95 \% \mathrm{Cl}: 0.77,1.14, \mathrm{I}^{2}: 0 \% ; \mathrm{p}=0.78$ ), significant association was found between DII and the risk of MetS ( $\triangleright$ Table 3). After removing the study of Wirth et al. [8] due to low quality, no significant changes in the pooled effect size was observed (pooled $R R=1.02 ; 95 \% \mathrm{Cl}=0.80,1.31 ; I^{2}: 47.4 \% ; p=12$ ). Additionally, when we removed one study [27] that examined dietary intake using 24-h dietary recall, the effect estimate did not change considerably (pooled RR=0.92; $95 \% \mathrm{Cl}: 0.77,1.09, \mathrm{I}^{2}: 0 \% ; \mathrm{p}=0.88$ ).

\section{Findings from meta-analysis on DII and the risk of all-cause mortality}

According to the results of a meta-analysis on five effect sizes, we reached significant association between DII and all-cause mortality (pooled HR $=1.21$; $95 \% \mathrm{Cl}: 1.09,1.35$ ) with highly severe heterogeneity ( $\left.I^{2}: 72.6 \% ; p=0.003\right)$ ( $>$ Fig. 4). To find the main cause that resulted in such noticeable heterogeneity, subgroup analysis was conducted. As represented in $>$ Table 3 , stratification by dietary assessment tool had the most effect on reducing the heterogeneity. There was significant differences between studies that used FFQ (pooled $\mathrm{HR}=1.11$; $95 \% \mathrm{Cl}: 1.02,1.20 ; \mathrm{I}^{2}: 35.6 \%, \mathrm{p}=0.21$ ) and $24-\mathrm{h}$ dietary recall (pooled $\mathrm{HR}=1.35 ; 95 \% \mathrm{Cl}: 1.21,1.49 ; \mathrm{I}^{2}: 0 \% ; \mathrm{p}=0.93$ ) to assess the association between DII and all-cause mortality.

\section{Findings from meta-analysis on DII and the risk of CVD mortality}

As presented in $>$ Fig. $\mathbf{4}$, the pooled effect size of six studies depicted significant association between DII and mortality from CVD (pooled HR: 1.30, $95 \% \mathrm{Cl}: 1.07,1.57$ ) with high heterogeneity ( $\mathrm{I}^{2}$ : $74.0 \%, p=0.009)$. Stratification by age, dietary assessment tool and energy adjustment removed the heterogeneity, completely $\left(\mathrm{I}^{2}=0 \%\right.$ for all). Moreover, the association in all sub-groups remained significant ( $\triangleright$ Table 3 ).

\section{Findings from meta-analysis on DII and the risk of cancer mortality}

The provided diagram illustrated that the most pro-inflammatory versus the most anti-inflammatory diet significantly increased the 

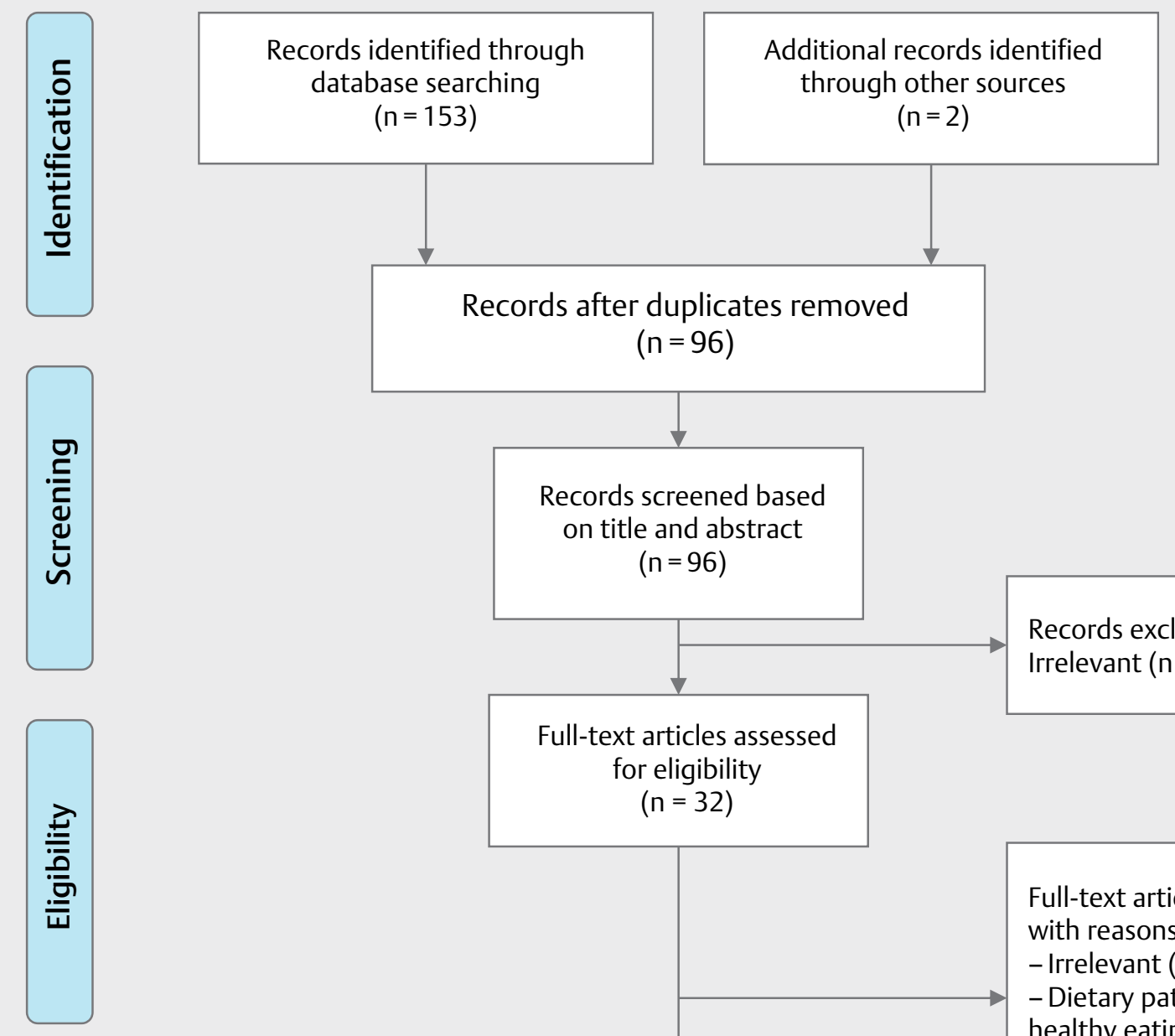
on title and abstract $(n=96)$
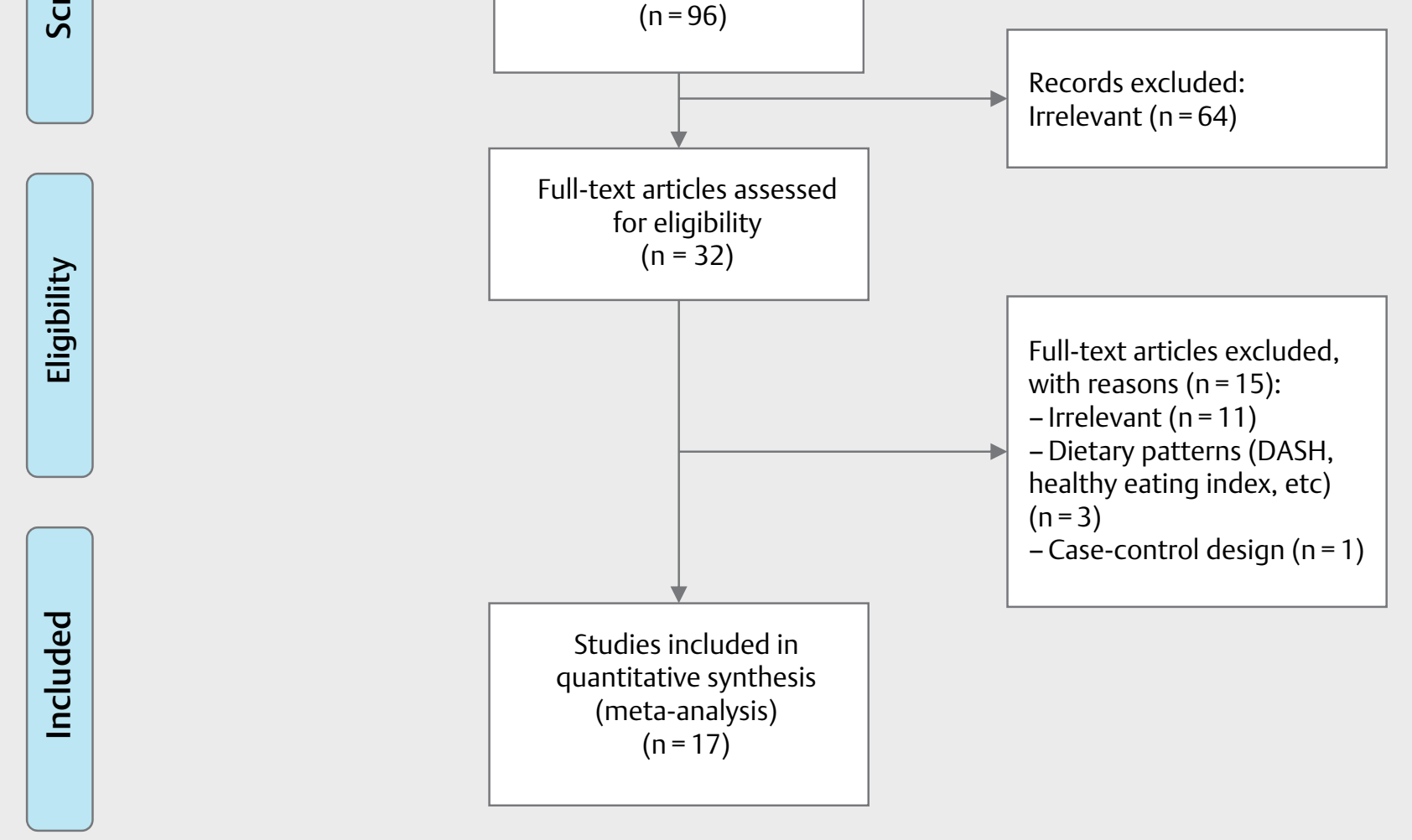

Studies included in quantitative synthesis (meta-analysis) $(n=17)$

- Fig. 1 Flow chart of screening stages to identify eligible papers.

risk of cancer mortality (pooled HR: 1.28, $95 \% \mathrm{Cl}: 1.07,1.53$; $\mathrm{I}^{2}$ : $62.5 \% ; p=0.03$ ) ( Fig. 4). As represented in \ Table 3, stratification by dietary assessment tool and energy adjustment attenuated the heterogeneity considerably. We found that the pooled HR in studies that used FFQ was $1.10\left(95 \% \mathrm{Cl}: 1.00,1.20, \mathrm{I}^{2}: 3.3 \%\right)$ and in studies whose dietary assessment tool was 24 -h dietary record was 1.45 (95\% Cl: $1.22,1.72 ;$ I $^{2}: 0 \%$ ). Furthermore, stratification by energy adjustment revealed that in studies that were adjusted for energy intake, the pooled HR was 1.10 (95\% Cl: 1.00, 1.20; $\mathrm{I}^{2}$ : $3.3 \%)$ whereas it was 1.45 (95\% Cl: $1.22,1.72$; $\mathrm{I}^{2}$ : $\left.0 \%\right)$ for non-adjusted studies for this confounder ( $\triangleright$ Table 3 ).

\section{Sensitivity analysis}

Based on sensitivity analysis, excluding none of studies affect noticeably the overall effect sizes for each aforementioned outcome.

\section{Publication bias}

The Egger's regression test confirmed no publication bias for CVD $(p=0.11)$ and mortality from CVD $(p=0.07)$ while it revealed the existence of publication bias for MetS $(p=0.96)$ and all-cause mortality $(p=0.08)$ as well as cancer mortality $(p=0.06)$. 


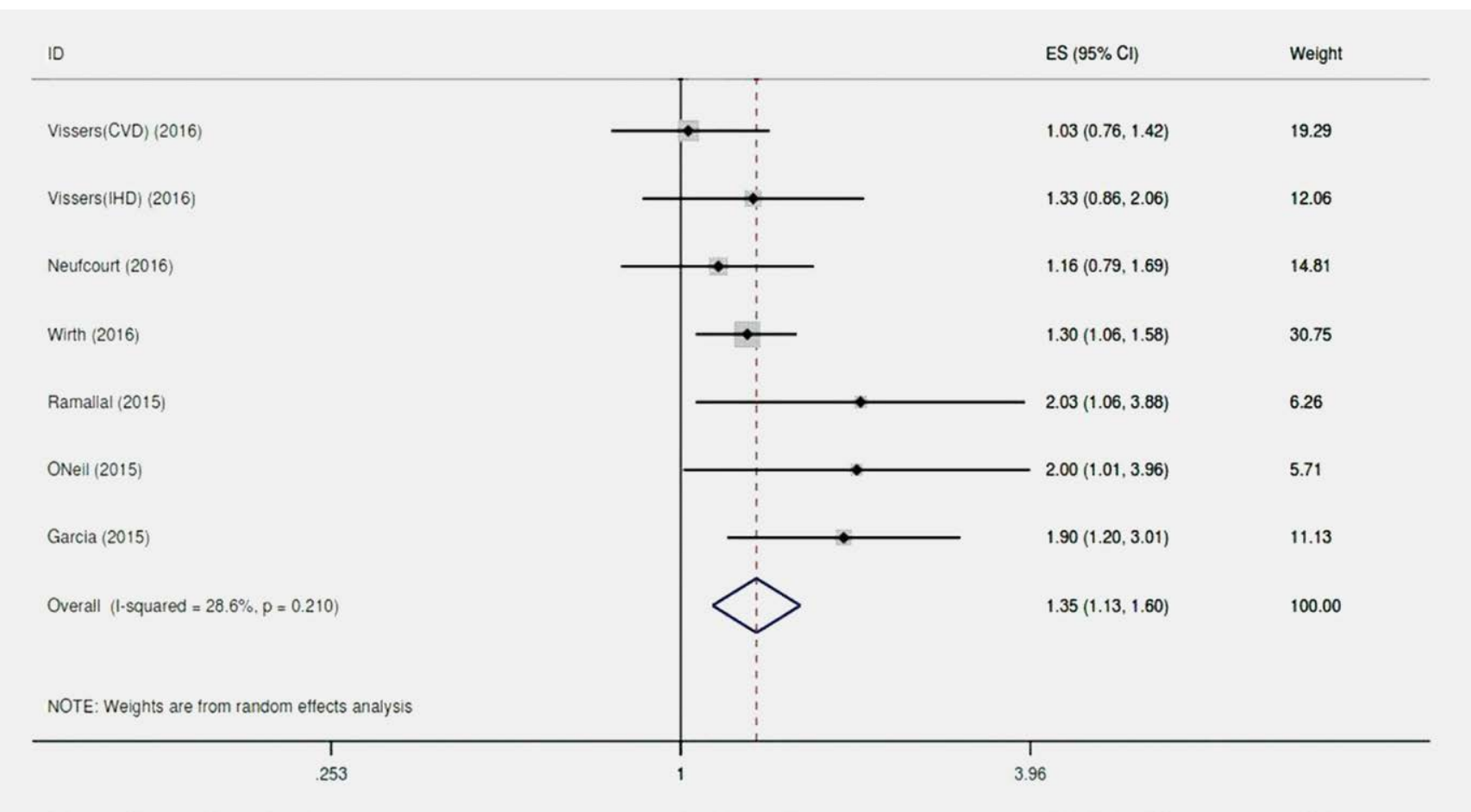

- Fig. 2 Forest plot of the association between dietary inflammatory index and the risk of cardiovascular diseases.

\section{Discussion}

According to the current meta-analysis, we found that the most pro-inflammatory versus the most anti-inflammatory diet was not associated with an increased risk of MetS. However, individuals with the most pro-inflammatory diet had a $35 \%$ higher risk for CVD than those with the most anti-inflammatory diet. Regarding mortality, we also obtained $21 \%, 30 \%$, and $28 \%$ higher risk for the occurrence of all-cause, CVD and cancer death in subjects with the most pro-inflammatory diet when compared to those with the most anti-inflammatory diets.

Subgroup analysis revealed that the association of DII with the risk for all-cause, CVD and cancer mortality in younger and non-American individuals was significantly greater than older and American populations. In addition, studies on all-cause, CVD and cancer mortality that used FFQ indicated lower link compared to those with 24-h dietary recall. Studies on CVD mortality that adjusted findings for energy intake demonstrated a lower association compared to non-adjusted ones.

To the best of our knowledge, the present study is the first meta-analysis that has summarized findings from previous studies on the association between the DII and CVD, MetS and mortality. Based on a narrative review by Ruiz-Canela et al., the DII can be a helpful tool to predict the inflammatory capacity of a diet. It can also clarify the association of diet and inflammation with CVD, MetS and mortality [4]. Since aforesaid study has included only qualified synthesis, making conclusion about significant association between the DII and the aforementioned outcomes as well as the quantitative rate of the association remains unclear.

There is accumulating evidence that have pointed to the associations between dietary exposures and biochemical parameters [4].
For instance, some studies have reported an association between the lower serum levels of CRP and a higher consumption of legumes [31], fruits and vegetable [32,33], and nuts [34]. Furthermore, chronic diseases including CVD, MetS, obesity, and cancer are associated with inflammatory biomarkers [C-reactive protein (CRP), Interleukin-1 $\beta$ (IL-1 $\beta$ ), IL-4, IL-6, IL-10 and tumor necrosis factor-alpha (TNF- $\alpha$ )] that have been considered in the DIl development [35].

In line with aforesaid evidence, some studies have revealed an inverse association between the DII and healthy dietary pattern such as the Altered Healthy Eating Index (AHEI) and DASH diet [30]. Western dietary patterns including the consumption of high fat, sweetened soft drinks, red meat, and fried foods are also associated with the high serum levels of hs-CRP while healthy dietary patterns are inversely associated $[11,12]$.

The current meta-analysis revealed that there was a significant association between DII and the risk for CVD. Mirroring our findings, Kaptoge et al., in a meta-analysis on 54 prospective studies, found an association between hs-CRP levels and high risk for coronary heart disease, stroke, and mortality from CVD [36]. In our meta-analysis, some studies examined dietary intake only at baseline. It is most likely that in a long-duration of study; changes in dietary habits will be occurred. Therefore, the assessment of dietary intake should be repeated in reasonable intervals throughout a study.

We could not detect the association between gender and CVD because all studies except two [5, 24] were conducted on men and women in combination. Moreover, all six studies except one [24] employed a cohort design. As cross-sectional design would not clarify a causal association, we excluded this study to obtain a real effect size. After excluding this study from meta-analysis, the pooled effect size fell to 1.33 . 
- Table 3 Subgroup analysis of the association between dietary inflammatory index and cardiovascular disease, metabolic syndrome and mortality.

\section{Outcome}

Pooled effect size $(95 \% \mathrm{Cl})$

\section{Number of} study

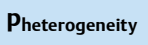

$I^{2}(\%)$

Pbetween

\section{CVD}

Assessment tool

FFQ

24-h dietary record

$1.49(1.11,2.01)$

$1.27(1.06,1.51)$

0.10

48.3

Energy adjustment

Adjusted

$1.27(0.99,1.63)$

0.60

0.53

Non-adjusted

$1.51(1.22,2.05)$

0.18

0

0.53

MetS

Study design

Cohort

Cross-sectional

$1.11(0.68,1.82)$

$0.94(0.77,1.14)$

0.04

75.5

0.78

0.24

All-cause mortality

Age

$\geq 49$ years old
$<49$ years old

\section{4}

2

$1.13(1.03,1.24)$

$1.33(1.21,1.46)$

0.17

0.82

38.5

29.4

0.40

Country

USA

$1.19(1.04,1.35)$

$1.27(1.10,1.47)$

0.002

0.55

0.003

Assessment tool

FFQ

24-h dietary record

$1.11(1.02,1.20)$

$1.35(1.21,1.49)$

0.21

0.93

0.0001

Energy adjustment

Adjusted

Non-adjusted

$1.26(1.12,1.42)$

$1.14(0.99,1.31)$

0.15

0.08

39

Follow-up

$\geq 12.5$ years

$<12.5$ years

$1.22(1.03,1.44)$

$1.21(1.04,1.41)$

0.15

0.002

0.2

\section{CVDs mortality}

Age

$\geq 49$ years old

$<49$ years old

$1.10(1.02,1.19)$

$1.48(1.26,1.75)$

\subsection{6}

0.81

0.001

Assessment tool

FFQ

24-h dietary record

$1.10(1.02,1.19)$

$1.48(1.26,1.75)$

0.36

0.81

0.001

Energy adjustment

Adjusted

Non-adjusted

$1.10(1.02,1.19)$

$1.48(1.26,1.75)$

0.36

0.81

0.001

\section{Cancer mortality}

Age

$\geq 49$ years old

$<49$ years old

Country

USA

Non-USA

2

Assessment tool

FFQ

24-h dietary record

$1.23(0.98,1.55)$

$1.40(1.16,1.69)$

$1.23(0.99,1.53)$

$1.43(1.00,2.04)$

$1.10(1.00,1.20)$

$1.45(1.22,1.72)$

\begin{tabular}{|c|c|}
\hline 0.07 & 60.9 \\
\hline 0.43 & 0 \\
\hline
\end{tabular}

0.02

$0.03+70.3$

$0.18 \quad 44.0$

0.14

0.30

0.45

3.3

0

0.005 
- Table 3 Continued.

\begin{tabular}{|c|c|c|c|c|c|}
\hline Outcome & $\begin{array}{l}\text { Number of } \\
\text { study }\end{array}$ & Pooled effect size ( $95 \% \mathrm{Cl})$ & Pheterogeneity & $I^{2}(\%)$ & Pbetween \\
\hline \multicolumn{6}{|c|}{ Energy adjustment } \\
\hline Adjusted & 2 & $1.10(1.0,1.20)$ & 0.30 & 3.3 & \multirow[b]{2}{*}{0.005} \\
\hline Non-adjusted & 3 & $1.45(1.22,1.72)$ & 0.45 & 0 & \\
\hline \multicolumn{6}{|l|}{ Follow-up } \\
\hline$\geq 12.5$ years & 3 & $1.23(1.01,1.50)$ & 0.03 & 71.6 & \multirow[b]{2}{*}{0.15} \\
\hline$<12.5$ years & 2 & $1.45(0.99,2.13)$ & 0.2 & 36.6 & \\
\hline
\end{tabular}

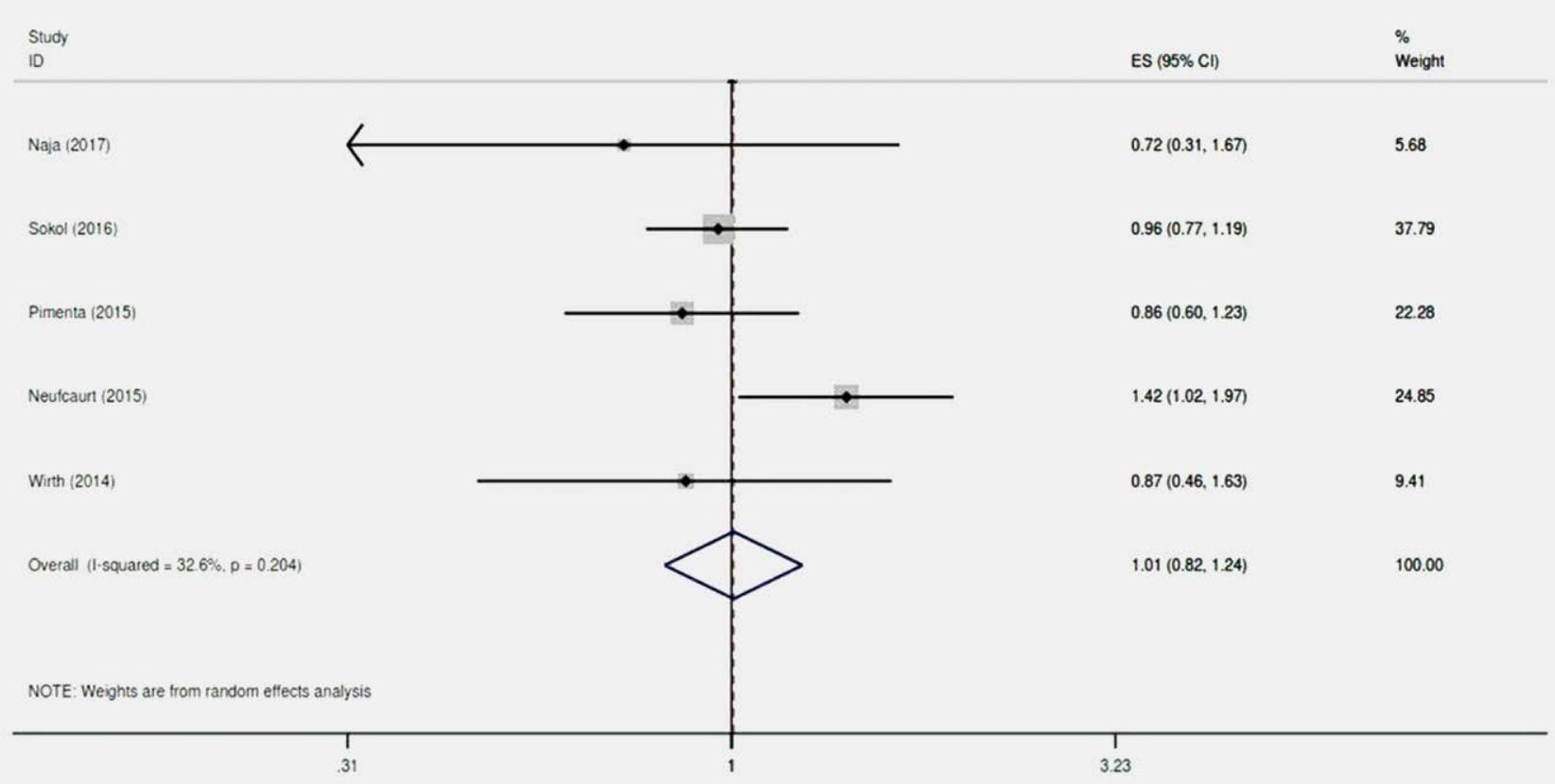

- Fig. 3 Forest plot of the association between dietary inflammatory index and the risk of metabolic syndrome.

High intake of refined carbohydrates, red and processed meats and French fries (foods with pro-inflammatory properties) can increase inflammatory cytokines, including serum levels of hs-CRP, soluble vascular cell adhesion molecule-1, and E-selectin. These inflammatory factors can result in insulin resistance and lipid disorders, which might be followed by the occurrence of CVD [15]. Since the DIl was obtained from up to 45 food items and nutrients, and could be representative of the inflammatory status of the whole food intake [35], it was predictable to observe an association between the DII and the risk of CVD.

With regard to MetS, we did not find any association. Since cross-sectional design cannot show the cause and effect relationship, we stratified studies by study design to clarify this association. In cohort studies, the highest DII score showed an $11 \%$ non-significant increase in the incidence of MetS compared to the lowest DII score. One important issue in studies on the association between dietary intake and diseases is how and by which tool dietary intake has been assessed. We can obtain more precise information via face-to-face interviews compared to self-reporting. Self-reporting is most probably causes misclassification bias. In Pimenta et al.'s study, dietary intake was collected through self-reporting. Moreover, at baseline the participants were considerably healthier than those in other American cohort studies [16]. The observed null association between the DII and disease incidence can be probably explained by these two issues.

It is noticeable that even in studies with a null association, a significant relationship between the DII and some features of MetS was found. Therefore, it seems that a different duration of exposure is needed to influence each component of MetS. The association between inflammation and disease is complex, and various factors including individual characteristics, race, and environmental parameters are involved while findings were adjusted for only limited factors in this meta-analysis. Discrepancies in results may be due to differences in race, gender, energy intake, as well as study 
Study

$\%$

ID

ES $(95 \% \mathrm{CI}) \quad$ Weight

all-cause mortality

Zaslavsky (2017)

Shivapa (2017)

Shivappa (2016)

Shivapa (2016)

Deng (2016)

Graffouilere (2016)

Subtotal $(\mathrm{I}$-squared $=72.6 \%, p=0.003$ )

CVD mortality

Shivapa (2017)

Shivappa (2016)

Shivapa (2016)

Deng (2016)

Subtotal $(\mathrm{I}$-squared $=74.0 \%, p=0.009$ )

Cancer mortality

Shivapa (2017)

Shivappa (2016)

Shivapa (2016)

Deng (2016)

Graffouilere (2016)

Subtotal $($ I-squared $=62.5 \%, p=0.030$ )

Overall (I-squared $=65.8 \%, p=0.000$ )

NOTE: Weights are from random effects analy sis

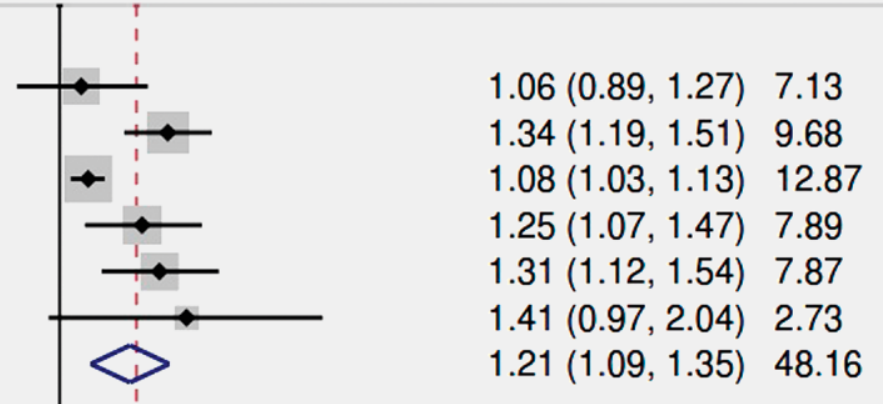

$1.46(1.18,1.81) \quad 5.87$

$1.09(1.01,1.18) 11.63$

$1.26(0.93,1.70) \quad 3.75$

$1.52(1.18,1.96) \quad 4.76$

$1.30(1.07,1.57) \quad 26.01$

$1.46(1.18,1.81) \quad 5.87$

$1.08(0.99,1.18) \quad 11.17$

$1.25(0.96,1.64) \quad 4.43$

$1.23(0.84,1.79) \quad 2.65$

$1.83(1.12,2.99) \quad 1.71$

$1.28(1.07,1.53) 25.83$

$1.23(1.15,1.32) \quad 100.00$

NOTE: Weights are from random effects analy

.334

1

2.99

Fig. 4 Forest plot of the association between dietary inflammatory index and the risk of all-cause, cardiovascular disease and cancer mortality.

quality; due to the limited number of studies, we could not examine the impacts of these factors in sub-group analysis.

In the present study, a significant association between DII and all-cause mortality was found. The heterogeneity for all-cause mortality was high, and we could not remove it using stratifications. However, after stratification by dietary assessment tool, it was attenuated considerably. Assessment tool can play a key role on examining dietary indices. The FFQ is a dietary checklist that can estimate how often and how much food are consumed over a specific period. Using an FFQ, particularly a semi-quantitative FFQ enables nutritionists to assess a long-term dietary intake. In addition, it can focus on the consumption of specific nutrients or certain dietary exposures related to a specific disorder. Although filling out an FFQ is time-consuming, it can cover a wide range of food items and its amount. Therefore, estimation of usual intake by FFQ is more accurate than 24-h dietary recall. However, dietary recall only can estimate types and the amounts of food in a short period of time. Taking less time to be filled out compare to FFQ is its positive point. However, it is necessary to know about portion size and estimate the amount of consumed food that can increase bias. Hence, FFQ can reflect usual dietary intake in a longer period of time compare to dietary recall, it can be a helpful method to examine the association between diet and diseases [37].

Our findings revealed that pro-inflammatory versus anti-inflammatory diet increased the risk for CVD mortality by $30 \%$. Similar to our findings, a meta-analysis revealed an association between pro-inflammatory cytokines (namely IL-6 and TNF- $\alpha$ ) and CVD mortality [38]. With regard to cancer mortality as an outcome, we reached a significant association. In the current meta-analysis, it was revealed that studies that did not control energy intake showed greater association compared to adjusted ones. As the more energy intake reflects the more food intake that can be assigned in both pro-inflammatory and anti-inflammatory foods, no attention to total energy intake can result in bias. Moreover, all the included studies in 
the meta-analysis that examined energy intake by 24-h dietary recall, asked subjects for usual energy intake for two or three times at the baseline and it was not repeated throughout the study. Therefore, any changes in dietary pattern maybe happened and affect the results. Thus, cohort studies examining dietary intake more than one throughout the study period are needed to making a certain decision on this association.

Our findings indicated that in non-American societies, the association between DII and mortality from all-cause and cancer was greater than American populations. As dietary pattern can affect the score of DII, such results might be observed. However in the present meta-analysis, there were limited studies on each subgroup and the heterogeneity in studies occurred in the USA was considerably high. Therefore, based on the existed studies, the effects of location on the association remained unclear. It is notable that American populations mostly adhere to Western diets, which contain high pro-inflammatory foods, while in different European countries such as Mediterranean regions, people have more tendency to consume healthy foods including seafood, vegetables, and fruits in their usual diet $[39,40]$. Thus, DII can be influenced by different dietary patterns and other lifestyles. In the present meta-analysis, only one study examined Asian population. Given that, the association between DII, chronic diseases and mortality in Asian populations remained unclear.

The present meta-analysis had some limitations. Due to different cut-off points for the DII score, we could not determine a specific range that might involve in the occurrence of CVD, MetS, and mortality. The impact of gender on this association also remained unclear. Additionally, due to less than two effect sizes in several subgroups, we could not examine their effects on association between DII and our outcomes. The strength of the current study is the determination of the association rate between the DII and the risk of CVD, MetS and mortality for the first time. Moreover, most of the included studies employed prospective design and had large sample size. This is second strength point of our study. Prospective design helps to minimize the potential recall and selection bias.

In conclusion, although the current meta-analysis did not show that the most pro-inflammatory diet was associated with the risk for MetS, we did observe substantial associations between the DII, risk for CVD and all-types of mortality. However, more prospective studies on each gender and in different societies are needed to clarify these associations.

\section{Author Contribution Statement}

The authors' responsibilities were as follows: B.L, L.A designed the research; N.N and L.A: conducted systematic research; N.N, L.A: extracted data; N.N, L.A, B.L: analyzed data; N.N, B.L and L.A: wrote the manuscript; B.L, L.A: had primary responsibility for the final contents of the manuscript; and all authors: read and approved the final manuscript.

\section{Acknowledgements}

We would like to express our thanks to Iran National Science Foundation (grant number: 96003297) for financial support.
Conflict of Interest

The authors declare that they have no conflict of interest.

\section{References}

[1] Ramallal R, Toledo E, Martínez-González MA, Hernández-Hernández A, García-Arellano A, Shivappa N. Dietary inflammatory index and incidence of cardiovascular disease in the SUN cohort. PloS One 2015; 4: $1-15$

[2] Barbaresko ], Koch M, Schulze MB, Nöthlings U. Dietary pattern analysis and biomarkers of low-grade inflammation: A systematic literature review. Nutr Rev 2013; 71: 511-527

[3] Vissers LE, Waller MA, van der Schouw YT, Hebert JR, Shivappa N, Schoenaker DA. The relationship between the dietary inflammatory index and risk of total cardiovascular disease, ischemic heart disease and cerebrovascular disease: Findings from an Australian population-based prospective cohort study of women. Atherosclerosis 2016; 253: $164-170$

[4] Ruiz-Canela M, Bes-Rastrollo M, Martínez-González MA. The role of dietary inflammatory index in cardiovascular disease, metabolic syndrome and mortality. Int J Mol Sci 2016; 17: 1265

[5] O’Neil A, Shivappa N, Jacka FN, Kotowicz MA, Kibbey K, Hebert JR. Pro-inflammatory dietary intake as a risk factor for CVD in men: A 5-year longitudinal study. Br J Nutr 2015; 114: 2074-2082

[6] Shivappa N, Steck SE, Hurley TG, Hussey JR, Ma Y, Ockene IS. A population-based dietary inflammatory index predicts levels of C-reactive protein in the Seasonal Variation of Blood Cholesterol Study (SEASONS). Public Health Nutr 2014; 17: 1825-1833

[7] Cavicchia PP, Steck SE, Hurley TG, Hussey JR, Ma Y, Ockene IS. A new dietary inflammatory index predicts interval changes in serum high-sensitivity C-reactive protein. J Nutr 2009; 139: 2365-2372

[8] Wirth M, Burch J, Shivappa N, Violanti JM, Burchfiel CM, Fekedulegn D. Association of a dietary inflammatory index with inflammatory indices and the metabolic syndrome among police officers. Int J Occup Environ Med 2014; 56: 986

[9] Neufcourt L, Assmann K, Fezeu L, Touvier M, Graffouillère L, Shivappa N. Prospective association between the dietary inflammatory index and metabolic syndrome: Findings from the SU. VI. MAX study. Nutr Metab Cardiovasc Dis 2015; 25: 988-996

[10] San KMM, Fahmida U, Wijaksono F, Lin H, Zaw KK, Htet MK. Chronic low grade inflammation measured by dietary inflammatory index and its association with obesity among school teachers in Yangon, Myanmar. Asia Pac J Clin Nutr 2018; 27: 92

[11] Julia C, Meunier N, Touvier M, Ahluwalia N, Sapin V, Papet I. Dietary patterns and risk of elevated C-reactive protein concentrations 12 years later. Br J Nutr 2013; 110: 747-754

[12] Nettleton JA, Steffen LM, Mayer-Davis EJ, Jenny NS, Jiang R, Herrington DM. Dietary patterns are associated with biochemical markers of inflammation and endothelial activation in the Multi-Ethnic Study of Atherosclerosis (MESA). Am J Clin Nutr 2006; 83: 1369-1379

[13] Garcia-Arellano A, Ramallal R, Ruiz-Canela M, Salas-Salvadó J, Corella D, Shivappa N. Dietary inflammatory index and incidence of cardiovascular disease in the PREDIMED study. Nutrients 2015; 7: 4124-4138

[14] Shivappa N, Blair CK, Prizment AE, Jacobs DR, Steck SE, Hébert JR. Association between inflammatory potential of diet and mortality in the lowa Women's Health study. Eur J Clin Nutr 2016; 55: 1491-1502

[15] Deng FE, Shivappa N, Tang Y, Mann JR, Hebert JR. Association between diet-related inflammation, all-cause, all-cancer, and cardiovascular disease mortality, with special focus on prediabetics: Findings from NHANES III. Eur J Nutr 2016; 56: 1085-1109 
[16] Pimenta AM, Toledo E, Rodriguez-Diez MC, Gea A, Lopez-Iracheta R, Shivappa N. Dietary indexes, food patterns and incidence of metabolic syndrome in a Mediterranean cohort: The SUN project. Clin Nutr 2015; 34: 508-514

[17] Sokol A, Wirth MD, Manczuk M, Shivappa N, Zatonska K, Hurley TG. Association between the dietary inflammatory index, waist-to-hip ratio and metabolic syndrome. Nutr Res 2016; 36: 1298-1303

[18] Shivappa N, Harris H, Wolk A, Hebert JR. Association between inflammatory potential of diet and mortality among women in the Swedish Mammography Cohort. Eur J Clin Nutr 2016; 55: 1891-1900

[19] Moher D, Liberati A, Tetzlaff J, Altman DG.Group P. Preferred reporting items for systematic reviews and meta-analyses: The PRISMA statement. Ann Intern Med 2009; 18: 264-269

[20] Stang A. Critical evaluation of the Newcastle-Ottawa scale for the assessment of the quality of nonrandomized studies in meta-analyses. Eur J Epidemiol 2010; 25: 603-605

[21] Higgins JP, Green S. Cochrane handbook for systematic reviews of interventions. Obtaining standard errors from confidence intervals and P values: Absolute (difference) measures. New York: Wiley; 2011

[22] Kerkhoffs GM, Servien E, Dunn W, Dahm D, Bramer JA, Haverkamp D. The influence of obesity on the complication rate and outcome of total knee arthroplasty. J Bone Joint Surg Am 2012; 94: 1839-1844

[23] Shivappa N, Steck SE, Hussey JR, Ma Y, Hebert JR. Inflammatory potential of diet and all-cause, cardiovascular, and cancer mortality in National Health and Nutrition Examination Survey III Study. Eur J Clin Nutr 2017; 6: 1-10

[24] Wirth MD, Shivappa N, Hurley TG, Hébert JR. Association between previously diagnosed circulatory conditions and a dietary inflammatory index. Nutr Res 2016; 36: 227-233

[25] Zaslavsky O, Zelber-Sagi S, Hebert JR, Steck SE, Shivappa N, Tabung FK, Wirth MD, Bu Y, Shikany JM, Orchard T, Wallace RB, Snetselaar L, Tinker LF. Biomarker-calibrated nutrient intake and healthy diet index associations with mortality risks among older and frail women from the Women's Health Initiative. Am J Clin Nutr 2017; 105: 1399-1407

[26] Graffouillère L, Deschasaux M, Mariotti F, Neufcourt L, Shivappa N, Hébert JR. Prospective association between the Dietary Inflammatory Index and mortality: Modulation by antioxidant supplementation in the SU. VI. MAX randomized controlled trial. Am J Clin Nutr 2016; 103: 878-885

[27] Neufcourt L, Assmann KE, Fezeu LK, Touvier M, Graffouillère L, Shivappa N, Hébert JR, Wirth MD, Hercberg S, Galan P, Julia C, Kesse-Guyot E. Prospective Association Between the Dietary Inflammatory Index and Cardiovascular Diseases in the Supplementation en VItamines et Mineraux AntioXydants (SU.VI.MAX) Cohort. J Am Heart Assoc 2016; 5: e002735 doi: 10.1161/JAHA.115.002735
[28] Shivappa N, Harris H, Wolk A, Hebert JR. Association between inflammatory potential of diet and mortality among women in the Swedish Mammography Cohort. Eur J Clin Nutr 2016; 55: 1891-1900

[29] Naja F, Shivappa N, Nasreddine L, Kharroubi S, Itani L, Hwalla N, Mehio Sibai A, Hebert JR. Role of inflammation in the association between the western dietary pattern and metabolic syndrome among Lebanese adults. Int J Food Sci Nutr 2017; 68: 997-1004

[30] Wirth MD, Hébert JR, Shivappa N, Hand GA, Hurley TG, Drenowatz C. Anti-inflammatory Dietary Inflammatory Index scores are associated with healthier scores on other dietary indices. Nutr Res 2016; 36: 214-219

[31] Hermsdorff HHM, Zulet MÁ, Abete I, Martínez JA. A legume-based hypocaloric diet reduces proinflammatory status and improves metabolic features in overweight/obese subjects. Eur JNutr 2011; 50: 61-69

[32] Hermsdorff HHM, Zulet MÁ, Puchau B, Martínez JA. Fruit and vegetable consumption and proinflammatory gene expression from peripheral blood mononuclear cells in young adults: A translational study. Nutr Metab 2010; 7: 42

[33] Esmaillzadeh A, Kimiagar M, Mehrabi Y, Azadbakht L, Hu FB, Willett WC. Fruit and vegetable intakes, $\mathrm{C}$-reactive protein, and the metabolic syndrome. Am J Clin Nutr 2006; 84: 1489-1497

[34] Casas-Agustench P, López-Uriarte P, Bulló M, Ros E, Cabré-Vila J, Salas-Salvadó J. Effects of one serving of mixed nuts on serum lipids, insulin resistance and inflammatory markers in patients with the metabolic syndrome. Nutr Metab Cardiovasc Dis 2011; 21: 126-135

[35] Shivappa N, Steck SE, Hurley TG, Hussey JR, Hébert JR. Designing and developing a literature-derived, population-based dietary inflammatory index. Public Health Nutr 2014; 17: 1689-1696

[36] Collaboration ERF. C-reactive protein concentration and risk of coronary heart disease, stroke, and mortality: An individual participant meta-analysis. Lancet 2010; 375: 132-140

[37] Shim JS, Oh K, Kim HC. Dietary assessment methods in epidemiologic studies. Epidemiol Health 2014; 36: 1-8

[38] Kaptoge S, Seshasai SRK, Gao P, Freitag DF, Butterworth AS, Borglykke A. Inflammatory cytokines and risk of coronary heart disease: New prospective study and updated meta-analysis. Eur Heart J 2013; 367:

[39] Esmaillzadeh A, Kimiagar M, Mehrabi Y, Azadbakht L, Hu FB, Willett WC. Dietary patterns and markers of systemic inflammation among Iranian women. J Nutr. 2007; 137: 992-998

[40] Maghsoudi Z, Azadbakht L. How dietary patterns could have a role in prevention, progression, or management of diabetes mellitus? Review on the current evidence. J Res Med Sci 2012; 17: 694-709 